\title{
Interventions designed to control postpasteurization contamination in high- temperature, short-time-pasteurized fluid milk processing facilities: A case study on the effect of employee training, clean-in-place chemical modification, and preventive maintenance programs
}

\author{
S. J. Reichler, ${ }^{1} \odot$ S. I. Murphy, ${ }^{1} \oplus$ A. W. Erickson, ${ }^{2} \odot$ N. H. Martin, ${ }^{1} \odot$ A. B. Snyder, ${ }^{3}$ and M. Wiedmann ${ }^{1 *} \oplus$ \\ ${ }^{1}$ Milk Quality Improvement Program, Department of Food Science, Cornell University, Ithaca, NY 14853 \\ ${ }^{2}$ Ecolab Inc., 655 Lone Oak Drive, Eagan, MN 55121 \\ ${ }^{3}$ Department of Food Science, Cornell University, Ithaca, NY 14853
}

\begin{abstract}
Postpasteurization contamination (PPC) with gramnegative bacteria adversely affects the quality and shelflife of milk through the development of flavor, odor, texture, and visual defects. Through evaluation of milk quality at 4 large fluid milk processing facilities in the northeast United States, we examined the efficacy of 3 strategies designed to reduce the occurrence of PPC in fluid milk: (1) employee training (focusing on good manufacturing practices) alone and (2) with concurrent implementation of modified clean-in-place chemistry and (3) preventive maintenance (PM) focused on replacement of wearable rubber components. Despite increases in employee knowledge and self-reported behavior change, microbiological evaluation of fluid milk before and after interventions indicated that neither training alone nor training combined with modified clean-inplace interventions significantly decreased PPC. Furthermore, characterization of gram-negative bacterial isolates from milk suggested that specific bacterial taxonomic groups (notably, Pseudomonas sequence types) continued to contribute to PPC even after interventions and that no major changes in the composition of the spoilage-associated microbial populations occurred as a consequence of the interventions. More specifically, in 3 of 4 facilities, gram-negative bacteria with identical $16 \mathrm{~S}$ rDNA sequence types were isolated on multiple occasions. Evaluation of a PM intervention showed that used rubber goods harbored PPC-associated bacteria and that PPC may have been less frequent following a PM intervention in which wearable rubber goods were replaced (reduction from $3 / 3$ samples with PPC before to $1 / 3$ samples after). Overall, our findings suggest that commonly used "broad stroke interventions" may have
\end{abstract}

\footnotetext{
Received January 11, 2020.

Accepted March 26, 2020.

*Corresponding author: mw16@cornell.edu
}

a limited effect on reducing PPC. Our case study also demonstrates the inherent complexities of identifying and successfully addressing sanitation problems in large and complex fluid milk processing facilities. For example, broad changes to sanitation practices without improvements in PM and sanitary equipment design may not always lead to reduced PPC. Our data also indicate that although short-term evaluations, such as pre- and post-tests for employee training, may suggest improvements after corrective and preventive actions, extensive microbial testing, ideally in combination with isolate characterization, may be necessary to evaluate return on investment of different interventions.

Key words: postpasteurization contamination, Pseudomonas, intervention, training, clean-in-place

\section{INTRODUCTION}

Though Louis Pasteur is often credited with the discovery of the pasteurization process, the first application of the principles of pasteurization to fluid milk was attributed to Soxhlet over 20 yr later (Soxhlet, 1886; Monrad, 1895). Pasteurization of fluid milk quickly became widespread, with numerous publications detailing how to accomplish it on both home and commercial scales (De Schweinitz, 1894; Russell, 1895; Smith, 1896). Early on, bacterial recontamination of pasteurized milk was recognized as a potential danger, particularly if the milk was extensively handled and exposed to the environment after pasteurization (e.g., cooling, bottling; Koehler and Tonney, 1911). This recontamination, commonly referred to as postpasteurization contamination (PPC), often leads to sensory deterioration and decreased shelf-life of milk (Thomas and Druce, 1969; Hayes et al., 2002; Martin et al., 2018). Postpasteurization contamination has been estimated to cause spoilage in about $50 \%$ of milk from processors in New York State (Alles et al., 2018; Reichler et al., 2018), likely contributing to the observation that 
$20 \%$ of milk is wasted at the consumer level in the United States (Buzby et al., 2014). The main organisms involved in PPC associated with finished product spoilage are heat-labile gram-negative bacteria, including Pseudomonas and the Enterobacteriaceae, which can be introduced into finished products from a variety of potential sources, including contaminated equipment, contaminated aerosols, and cross-contamination from employees (Sunga et al., 1970; Schröder, 1984; Eneroth et al., 2000b). Although thermoresistant gram-positive bacteria, including sporeformers, could also be introduced after pasteurization (Eneroth et al., 2001), endospores formed by these bacteria are often present in the raw milk supply (Murphy et al., 2019) and endospore numbers are typically not reduced by HTST. While psychrotolerant sporeformers and, to a much lesser extent, non-spore-forming gram-positive bacteria cause fluid milk spoilage, they are thus excluded from our PPC definition used in this publication.

The PPC in HTST fluid milk processing facilities can range from $100 \%$ prevalence (meaning all containers show evidence of PPC) to prevalence $<1 \%$. Frequency of PPC within a facility can also vary widely between processing days (Reichler et al., 2018). Factors that contribute to increased likelihood of PPC vary widely and include personal hygiene, operational (e.g., preventive maintenance; $\mathbf{P M}$ ), and sanitation practices. Consequently, it is difficult to determine which strategies are most likely to reduce PPC in a given facility. Enhancements in different areas [e.g., good manufacturing practices (GMP), PM, and sanitation] may be needed to reduce PPC. For example, failure to consistently observe appropriate GMP may result in microbial contamination of milk by increasing the risk that bacteria are transferred from environmental sources to products. Good manufacturing practices are the prerequisite requirements for facilities, processing equipment, and personnel to produce food that is safe to eat, and adherence is federally mandated in the United States (Padilla-Zakour, 2009). Despite their mandatory status, compliance with appropriate and comprehensive GMP may not be universal and may include issues such as bacterial harborage in the facility environment, failure to perform necessary PM on equipment, and cross-contamination by workers. Preventive maintenance refers to a range of activities intended to prevent or delay the breakdown of equipment due to prolonged use. A regular schedule of PM has been linked to improved product quality and less unscheduled equipment downtime due to emergency repairs, which may be associated with increased likelihood of PPC (Tsarouhas, 2007; Zugarramurdi et al., 2007).

Sanitation in large-scale modern milk production is commonly managed using a clean-in-place (CIP) methodology, which has reduced the incidence of PPC (Havighorst, 1957; Moerman et al., 2014). Cleaning-inplace is an automated system that circulates cleaning and sanitizing solutions through piping and processing equipment without prior disassembly (Burgess, 2009). The CIP technology addresses microbial contamination caused by direct contact of fluid milk with contaminated internal pipe, valve, and processing equipment surfaces. Poorly implemented CIP programs are characterized by improper chemical choices or concentrations, unsuitably designed equipment, and infrequent sanitation cycles, among other design issues. For instance, the inclusion of dead ends in processing lines prevents the successful application of CIP to the entire system, and the misplacement of spray balls in bulk tanks has resulted in shadowing, where sanitizing agents are not uniformly applied to interior surfaces (Asteriadou and Fryer, 2009). Additionally, appropriately developed and implemented facility cleaning and sanitation is important, as the general environment of a facility can be a source of PPC.

In milk processing facilities with a high incidence of PPC, strategic interventions addressing GMP, sanitation, and other shortcomings are essential to address this problem. Appropriate root cause analysis procedures to identify the most effective interventions are also an essential part of reducing PPC. Interventions may, for example, target bacterial harborage sites in the processing environment and equipment and the transfer of bacteria from the processing facility environment to food contact surfaces (e.g., filler nozzles) or directly to milk (e.g., due to condensation or water spray; Moseley, 1980). Previously utilized interventions have included improved employee training (e.g., on GMP), altered employee GMP, use of enhanced CIP sanitizer chemistries, revised scheduling of sanitation shifts, enhanced PM of equipment, and improved hygienic equipment design. However, economically viable interventions must balance enhanced milk quality outcomes with resource utilization (Zugarramurdi et al., 2007). To assess different strategies to control PPC of HTST fluid milk, the study reported here applied 3 commonly used interventions in 4 large dairy processing facilities, with subsequent assessment of training efficacy as well as PPC frequency and spoilage patterns.

\section{MATERIALS AND METHODS}

\section{Processing Facility Recruitment}

We recruited 4 dairy processing facilities who had participated in our previous study examining the prevalence and diversity of PPC (Reichler et al., 2018). Facilities will be referred to according to their blinded 
names from this prior study: facilities C, G, D, and I. All 4 processing facilities were located in the northeast United States, manufactured HTST-pasteurized fluid milk for sale to retail consumers, and experienced persistent gram-negative PPC in a portion of their products based on prior testing and characterization of spoilage bacteria (Reichler et al., 2018). Facilities C and G were selected to receive only employee training as an intervention. Facilities D and I received employee training along with a modified CIP program that included an updated sanitizer regimen specifically targeting biofilm removal (further described below). Data were also collected on milk quality outcomes at facility D following a PM intervention. The annual production volume of the participating facilities ranged from 10 million to over 100 million liters of product. The facilities used between 4 and 10 package fillers and employed between 51 and 200 employees each. The facilities generally had 2 daily production shifts and 1 daily cleaning and sanitation shift. The sanitation shifts typically occurred in the evening, between 2200 and $0600 \mathrm{~h}$.

\section{Training Intervention Development, Delivery, and Efficacy Assessment}

We conducted employee training at all 4 processing facilities. Previously, we conducted a survey of the quality assurance managers of 10 fluid milk processing facilities (including the 4 in this study) in the northeast United States to inform the design of an appropriate employee training session on quality issues caused by PPC (data not shown). The training consisted of 3 modules designed to increase awareness of bacterial spoilage, bacterial harborage in food processing facilities, and routes of bacterial cross-contamination. Specific topics taken from the survey of quality assurance managers included PM, cleaning and sanitation standard operating procedures, and control of hygiene practices. The curriculum consisted of an approximately 40-slide PowerPoint (Microsoft Corp., Redmond, WA) presentation, which was image-intensive and included video of correct and incorrect sanitation practices. The training has since been utilized in $>10$ trainings for $>100$ dairy food processing facility employees in various university extension programs outside of this in-facility application.

Training and modified CIP interventions were implemented over a 1- or 2-d period for each facility. The training was presented to the filler operators, cleaning crew, maintenance staff, supervisors, and laboratory technicians at each processing facility. The number of participants at each facility ranged from 15 to 33 . Trainings were delivered in American English. All trainees had a working or vocational knowledge of English and were previously trained by supervisors in English at their facilities. The training was held in either a conference room or a break room and lasted approximately $1 \mathrm{~h}$. Multiple training sessions were offered over the course of 1 to $2 \mathrm{~d}$ to accommodate different employee schedules and to allow for continuous facility operation. At facilities C, G, and I, the trainees were asked to complete a short anonymous survey immediately before training and immediately following its conclusion. The survey at both time points was identical and asked each trainee to list what they believed were the 3 most important factors affecting milk quality or spoilage in their processing facility. The choices provided were raw milk, water use in the processing facility, workers' hands, unclean equipment, old equipment, and an old building. Trainees were also invited to write in their own selections.

Quality assurance managers at all 4 processing facilities were mailed a packet of follow-up surveys 6 to 8 mo after the training to administer to all employees that had participated in the training. The surveys asked 5 questions designed to assess self-reported changes in policies and behaviors (Figure 1B). Questions on the follow-up survey were forced response (yes, no, or don't know/NA). The completed surveys were collected by facility quality assurance personnel and returned via mail in a pre-addressed, postage-paid envelope within 3 to 4 wk of receipt. No incentive was offered for participation in either the training or in completion of the follow-up survey. Participation was voluntary, and results of the follow-up survey were confidential by individual and aggregated within each facility.

\section{Chemical Intervention to CIP Systems}

Chemical interventions to CIP systems were designed to minimize PPC due to direct milk contact with contaminated internal processing equipment surfaces. The CIP interventions were developed in consultation with a large national chemical supplier and consisted of modification of the chemical regimen at facilities D and I to include a peracid detergent and water conditioner (gluconic acid) pretreatment, an alkaline detergent override, an alkaline detergent wash, an acid detergent wash, and a heated peracid sanitization. Specifically, the peracid detergent pretreatment, alkaline override, and heated sanitization steps differentiate this treatment from a typical dairy processing facility CIP cycle (Table 1). The CIP interventions were performed with the cooperation and assistance of facility management. All pipes, valves, and machinery that handled pasteurized milk and were connected for treatment within the CIP circuits received this chemical intervention. The modified CIP treatment was implemented concurrently 


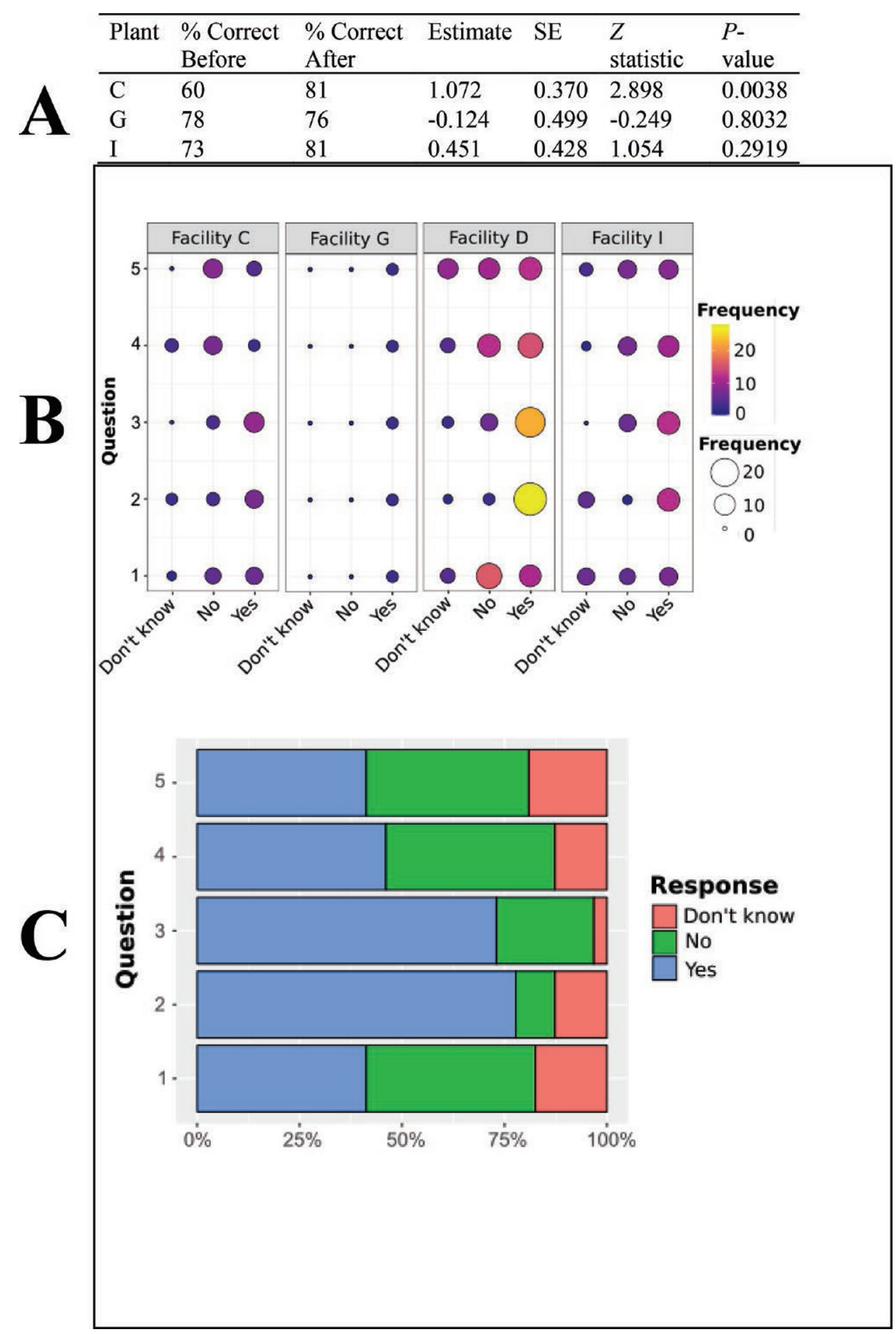

Figure 1. Outcomes of a training intervention targeted toward reducing persistent postpasteurization contamination. (A) Estimated marginal means pairwise comparisons calculated from a binomial logistic regression for rates of correct employee responses to a single survey question administered before and after training at processing facilities C, G, and I. (B) Trained employee self-reported behavioral changes 8 mo after attendance of a training exercise, separated by processing facility. Questions are denoted by number on the y-axis and are as follows: (1) Since attending the training, have you used the sanitizer and water hoses less often during processing? (2) Since attending the training, have you washed your hands more often while working on the filler? (3) Since attending the training, have you reported concerns in the plant to your supervisor or to maintenance? (4) Since attending the training, have you changed other behaviors while working in the plant? (5) Since attending the training, have plant sanitation policies changed? Frequency of responses is indicated both by color gradient and by circle area. (C) Trained employee self-reported behavioral changes 8 mo following attendance of training exercise, pooled across all processing facilities. Questions are denoted by number on the $\mathrm{y}$-axis and are listed in the caption for panel B. 
Table 1. Clean-in-place (CIP) chemistry and parameters used for typical dairy processing facility sanitation and a modified chemical intervention targeted toward persistent postpasteurization contamination, which was used in this study

\begin{tabular}{|c|c|c|c|c|c|c|}
\hline \multirow[b]{2}{*}{ Step } & \multicolumn{3}{|c|}{ Typical dairy processing facility CIP } & \multicolumn{3}{|c|}{ Modified CIP intervention } \\
\hline & $\begin{array}{l}\text { Product and } \\
\text { concentration } \\
\text { (\% vol/vol) }\end{array}$ & $\begin{array}{l}\text { Temperature } \\
\left({ }^{\circ} \mathrm{C}\right)\end{array}$ & $\begin{array}{l}\text { Time } \\
(\min )\end{array}$ & $\begin{array}{l}\text { Product and } \\
\text { concentration } \\
(\% \text { vol/vol) }\end{array}$ & $\begin{array}{l}\text { Temperature } \\
\qquad\left({ }^{\circ} \mathrm{C}\right)\end{array}$ & $\begin{array}{l}\text { Time } \\
(\mathrm{min})\end{array}$ \\
\hline Pre-rinse & Water $100 \%$ & $7-21$ & 10 & Water $100 \%$ & $7-21$ & 10 \\
\hline Pretreatment & Not performed & - & - & $\begin{array}{l}\text { Peracid detergent } 0.5 \% \text {, } \\
\text { Water conditioner } 0.1 \%\end{array}$ & 60 & 15 \\
\hline Rinse & Water $100 \%$ & $7-21$ & 10 & Water $100 \%$ & $7-21$ & 10 \\
\hline Acid wash & Acid detergent $1 \%$ & 71 & 30 & Acid detergent 1\% & 71 & 30 \\
\hline Rinse & Water $100 \%$ & $7-21$ & 10 & Water $100 \%$ & $7-21$ & 10 \\
\hline Sanitize & Peracid sanitizer $0.18 \%$ & $7-21$ & 15 & $\begin{array}{l}\text { Mixed peracid sanitizer } \\
0.16 \%\end{array}$ & 60 & 15 \\
\hline
\end{tabular}

with employee training, and milk sample collection (described below) was performed after startup on the following production shift.

\section{PM Interventions to Equipment}

A PM program intervention was applied to a specific production line at facility $\mathrm{D}$ with a history of highdiversity and high-prevalence PPC. During the time frame of the case evaluation, the facility PM schedule indicated that a manufacturer-performed change of all wearable (i.e., capable of becoming worn out through repeated use) rubber goods was due to be performed on Gable-Top Carton Filler 2 (Evergreen Packaging, Memphis, TN) in September 2017. To contrast the outcomes of this final intervention with other treatments, an additional application of the modified CIP chemistry was performed 1 mo before rubber goods replacement. The PM consisted of a complete replacement of all wearable rubber goods (i.e., gaskets, O-rings) within Gable-Top Carton Filler 2, preceded and followed by typical (i.e., non-intervention) CIP cycles. The 85 articles of used rubber goods removed from the filler were aseptically collected in individual sterile sample bags and transported to the Milk Quality Improvement Program laboratory at a temperature $<6^{\circ} \mathrm{C}$ for testing. Upon receipt, the rubber goods were stored at $4^{\circ} \mathrm{C}$ until testing. The rubber goods were separated by location within the filler into 9 groups $(1 \mathrm{~A}, 1 \mathrm{~B}, 2 \mathrm{~A}, 2 \mathrm{~B}, 3 \mathrm{~A}$, $3 \mathrm{~B}, 4 \mathrm{~A}, 4 \mathrm{~B}$, and $\mathrm{PV}$ ) and commingled by group into single sterile stomacher bags (Nasco, Fort Atkinson, WI). To enrich the commingled samples, $250 \mathrm{~mL}$ of room temperature brain heart infusion (BHI) broth (BD, Sparks, MD) was added to each bag and the bags were stomached at $260 \mathrm{rpm}$ for $60 \mathrm{~s}$ in a Stomacher 400 Circulator (Seward, Basingstoke, UK). Immediately following stomaching and again after $14 \mathrm{~d}$ of incuba- tion at $6^{\circ} \mathrm{C}, 50-\mu \mathrm{L}$ aliquots of each enrichment were streaked in duplicate onto crystal violet tetrazolium agar (CVTA; Frank and Yousef, 2004) plates, which were then incubated at $21^{\circ} \mathrm{C}$ for $48 \mathrm{~h}$. Results were interpreted as positive or negative for gram-negative bacteria based on the growth or absence, respectively, of typical colonies; isolates were collected, stored, and characterized as for the milk samples described below.

\section{Sample Collection and Shelf-Life Testing}

For each of the 4 processing facilities, samples of finished product were collected approximately $1 \mathrm{wk}$ before either (1) training or (2) training and the CIP intervention were performed. At processing facilities $\mathrm{C}$ and $\mathrm{G}$, which received only training as an intervention, follow-up samples were collected on 3 sample collection dates after training occurred, which consisted of (1) 1 mo after training, (2) 2 to 3 mo after training, and (3) 7 to 8 mo after training. For processing facilities D and I, which received both training and the modified CIP intervention, samples were collected (1) during the initial processing run performed after completion of training and application of the modified CIP intervention, (2) 2 to $3 \mathrm{mo}$ after the intervention, and (3) 7 to $8 \mathrm{mo}$ after the intervention. For facility D, which received an additional CIP intervention and a PM intervention, there were 6 sample collection dates, including (1) before the first CIP intervention (all available fillers), (2) after the first CIP intervention (samples from all available fillers), (3) after the second CIP intervention (samples from 1 filler only), (4) before the PM intervention (samples from 1 filler only), (5) after the PM intervention (samples from 1 filler only), and (6) 6 mo after the first CIP intervention (samples from all available fillers). With this scheme, we ensured that 3 full milk quality data sets were collected either after the training 
or after the training and CIP intervention for all available fillers for each of the 4 facilities.

To collect milk samples, sealed containers of HTSTpasteurized skim, $2 \%$ fat, and chocolate milk were collected from each filler used to produce consumer-sized plastic bottles (e.g., US gallon, half-gallon, quart, and so on) or single-serve paper cartons (1/2 US pint) of these products. Samples were packed with ice packs or ice into hard-sided coolers and shipped overnight at a temperature $<6^{\circ} \mathrm{C}$ to the Milk Quality Improvement Program laboratory. Samples were typically received within $3 \mathrm{~d}$ of packaging. After receipt, samples were held at $4^{\circ} \mathrm{C}$ for no more than $1 \mathrm{~d}$ before testing began. Multiple containers of milk were aseptically commingled, if necessary, to obtain a sufficient volume for testing (e.g., $6 \times 237 \mathrm{~mL}$ single-serve containers were commingled to obtain the necessary volume). For every sample, approximately $300 \mathrm{~mL}$ of product was aseptically transferred into each of 4 sterile polypropylene 500-mL screw-top bottles (Nalgene, Waltham, MA) for testing on separate days of shelf-life. Sample division was performed to avoid excessive disruption of the product headspace and to reduce the risk of contamination due to repeated sampling during shelf-life. Samples were held at $6^{\circ} \mathrm{C}$ for the remainder of the experiment.

For microbiological testing, each sample was serially diluted in PBS (Weber Scientific, Hamilton, NJ), if necessary, and spiral plated (Autoplate 5000, Advanced Instruments, Norwood, MA) in duplicate onto Standard Methods Agar (Merck KGaA, Darmstadt, Germany) to determine SPC and onto CVTA to determine total gram-negative counts (Frank and Yousef, 2004; Laird et al., 2004). The SPC plates were incubated at $32^{\circ} \mathrm{C}$ for $48 \mathrm{~h}$, and CVTA plates were incubated at $21^{\circ} \mathrm{C}$ for 48 $\mathrm{h}$. Plate counts were enumerated and recorded using a QCount automated counting system (Advanced Instruments). The milk samples were tested on the initial day of the experiment and on $\mathrm{d} 7,10,14,17$, and 21 of shelf-life postpasteurization, or until the SPC reached $>1 \times 10^{6} \mathrm{cfu} / \mathrm{mL}$ on 2 consecutive days of shelf-life testing. The milk samples for $\mathrm{d} 7$ and 10 of testing were drawn from the same $300-\mathrm{mL}$ aliquot, and samples for the other $3 \mathrm{~d}$ of testing were drawn from their own separately bottled aliquots, as is standard practice for the Cornell Voluntary Shelf-Life Program (Martin et al., 2012).

\section{Isolate Collection and Initial Characterization}

From each sample on each day of shelf-life testing, a minimum of 2 colonies, if present, representing typical gram-negative morphology on CVTA (i.e., smooth, circular, deep red colonies) were selected from the
CVTA plates for further characterization. From each sample with an SPC $>20,000 \mathrm{cfu} / \mathrm{mL}$ that was plated on a given day of shelf-life, all visually distinct colony morphologies observed on SPC were selected for isolation and further characterization. The selected colonies from both CVTA and SPC plates were isolated on BHI agar (BD), which was incubated at $32^{\circ} \mathrm{C}$ for $48 \mathrm{~h}$. An isolated colony from the BHI plate was then inoculated into $5 \mathrm{~mL}$ of BHI broth, which was incubated overnight at $32^{\circ} \mathrm{C}$ and subsequently frozen with $15 \%$ glycerol at $-80^{\circ} \mathrm{C}$. Records for all 1,029 gram-positive and gramnegative bacterial isolates obtained during this study, including characterization, subtyping, and sample information, were deposited in Food Microbe Tracker (http://www.foodmicrobetracker.com/; Vangay et al., 2013), and are biobanked in our laboratory bacterial isolate collection.

Bacterial cell lysates were prepared from an overnight culture in BHI broth. Briefly, $250 \mu \mathrm{L}$ of each culture was pelleted by centrifugation and resuspended in $95 \mu \mathrm{L}$ of $1 \times$ PCR buffer (Promega, Fitchburg, WI). Lysozyme (Thermo Fisher, Waltham, MA) was added to a concentration of $3 \mathrm{mg} / \mathrm{mL}$ and the solution was incubated at room temperature for $15 \mathrm{~min}$. Proteinase K (Roche Diagnostics, Mannheim, Germany) was then added to a concentration of $0.4 \mathrm{mg} / \mathrm{mL}$, and the solution was incubated for $1 \mathrm{~h}$ at $58^{\circ} \mathrm{C}$ and $10 \mathrm{~min}$ at $95^{\circ} \mathrm{C}$ in an ABI 2720 thermal cycler (Thermo Fisher). Lysates were refrigerated at $4^{\circ} \mathrm{C}$ or frozen at $-20^{\circ} \mathrm{C}$ until the time of use.

For each isolate, an approximately 765-bp internal fragment of the $16 \mathrm{~S}$ rDNA was amplified via PCR, purified, and Sanger sequenced using dye terminator chemistry as previously described (Reichler et al., 2018). The forward and reverse annotated sequence chromatograms were assembled, trimmed, and proofread to ensure high quality using Sequencher 5.4.5 (Gene Codes Corporation, Ann Arbor, MI). Genuslevel identification of these consensus sequences was done using SequenceServer, a local implementation of BLAST (Priyam et al., 2015), to search against the Ribosomal Database Project collection of 16S rDNA sequences (Cole et al., 2009).

\section{Isolate Subtyping}

All isolates that were identified as belonging to gramnegative genera by their $16 \mathrm{~S}$ rDNA sequences were further characterized as previously described (Reichler et al., 2018). Briefly, 16S rDNA sequences were aligned and trimmed to an approximately 552-bp region, and a unique numerical sequence type (ST) was assigned for each unique nucleotide sequence. An ST was considered 
unique if it differed by 1 or more nucleotide substitutions from any previously identified ST.

A subset of 41 Pseudomonas isolates belonging to ST 13 and isolated from milk samples and rubber goods from Gable-Top Carton Filler 2 at processing facility D were further characterized by sequencing their $g \ln S$ and $r e c A$ genes as previously described (Andreani et al., 2015). Briefly, bacterial lysates were prepared as for 16S PCR and were used as a template for 2 separate PCR targeting internal regions of the genes $g \ln S$ and recA (Supplemental Table S1; https://doi.org/10.3168/ jds.2020-18186). The PCR products were purified, sequenced, and edited as for $16 \mathrm{~S}$ rDNA PCR and sequencing. Edited sequences were aligned and trimmed using AliView (Larsson, 2014). Allelic types (AT) for both genes were assigned for each unique sequence. A sequence was considered unique if it differed by 1 or more nucleotide substitutions from that of any previously identified AT. To construct a phylogenetic tree of all unique $g \ln S$-recA alleles, $g \ln S$ and $r e c A$ sequences were concatenated to produce single sequences of 936 bp. A maximum likelihood tree was constructed using RAxML version 8.2.9 (Stamatakis, 2014) and the following settings: General Time Reversible model with optimization of substitution rates, GAMMA model of rate heterogeneity, and rapid bootstrap analysis with 1,000 iterations. A partition was applied to the sequence alignment so that $\alpha$-shape parameters, General Time Reversible substitution rates, and empirical base frequencies were estimated and optimized for $g \ln S$ and recA separately. The resulting tree was visualized using FigTree (1.4.2; http://tree.bio.ed.ac.uk/software/ figtree/).

\section{Statistical Analysis}

The pre- and post-training surveys were tabulated and the counts of responses deemed correct (i.e., water use in the processing facility, workers' hands, unclean equipment, or similar write-in responses) or incorrect, given the content of the training, were used as the response variable in a binomial logistic regression model constructed using the lme4 package in $\mathrm{R}$ (Bates et al., 2015; R Core Team, 2019). Processing facility, time of survey collection (i.e., before or after the training), and the interaction between facility and time were used as fixed effects for the model. Post-hoc comparisons were performed on this model using the emmeans package (https://cran.r-project.org/web/packages/emmeans/ index.html) to determine if significant differences in the level of correct survey responses before and after training existed in each facility. The frequencies of spoilage due to PPC over the 4 sampling points ( 1 point before intervention and 3 after) were assessed using $\chi^{2}$ tests with Monte Carlo simulated $P$-values and the Holm method of multiple comparison correction in $\mathrm{R}$.

\section{RESULTS AND DISCUSSION}

\section{Participation in Training Had Variable Efficacy on Modifying Employee Beliefs Regarding Milk Quality}

Trained employees at facilities C, G, and I were surveyed immediately before and after the 1-h training presentation regarding their beliefs on the 3 most important factors affecting milk quality and spoilage at their facility. At facility C, $60 \%$ of responses were correct before training, and $81 \%$ of responses were correct following training $(P=0.0038$; Figure $1 \mathrm{~A})$. At facility $\mathrm{G}, 78 \%$ of responses were correct before training, and $76 \%$ of responses were correct following training $(P=$ $0.80)$. At facility I, $73 \%$ of responses were correct before training, and $81 \%$ of responses were correct following training $(P=0.29)$. Only facility $\mathrm{C}$ exhibited a significant change in the frequency of correct responses, and facility $\mathrm{C}$ is also the only facility of the 4 that did not hold regular employee training sessions. Similar examinations of pre- and post-training questionnaires to assess training efficacy have been used in several food safety and hygiene training studies, many of which concluded that training resulted in significant improvements in knowledge, as it did at facility C (Egan et al., 2007). By comparison, facilities $\mathrm{G}$ and I had preexisting training programs, which may have accounted for their nonsignificant changes in correct responses. Similar results were reported by Ehiri et al. (1997), who concluded that food safety training does not necessarily result in significant improvements in pre-training knowledge and may be dependent on the type of content presented. Our pre- and post-training survey results may suggest that an intervention consisting of retraining employees on information they have been given previously is unlikely to result in significantly increased knowledge.

\section{Employee Self-Reported Changes to Behaviors}

Results of the follow-up long-term surveys for selfreported behavior change collected 6 to 8 mo after the training indicated that trained employees believed that their actions and behaviors had changed. In total, 63 completed surveys from trained individuals were received. The responses from facility $\mathrm{G}$ are notable because only 2 surveys were returned by employees who self-reported attending the training. Facility D had the largest number of respondents $(\mathrm{n}=31)$, and in general the results from facility $\mathrm{D}$ resembled those from facilities $\mathrm{C}$ and I (Figure 1B). At facilities C, D, 
and I, the largest proportion of trained employees responded "yes" to questions regarding positive behavior changes following the training. When results from all 4 facilities were combined, $41 \%$ of respondents indicated that they used the sanitizer hose less often during processing, a major objective of the training (Figure 1C). The majority of respondents reported more frequent handwashing (78\%) and notifying their supervisors of sanitation concerns (73\%) since attending the training, and $46 \%$ reported changing other unspecified behaviors since attending the training. When asked if sanitation policies at their processing facility had changed since the training, approximately equal numbers of employees responded yes and no ( $41 \%$ and $40 \%$, while $19 \%$ were unsure). Survey responses specifically from facility managers indicated that no facilities had changed their sanitation policies (data not shown); however, individual employee practices may have changed following the training. By comparison, a recent training study conducted on cheesemakers in Pennsylvania found that training was effective for increasing food safety knowledge but not for improving food safety attitudes and behaviors as measured by observation (Machado and Cutter, 2018). A study of food handlers in Brazil reached the similar conclusion that food safety training improved knowledge but not attitudes or practices (da Cunha et al., 2014). Similarly, a study in the United Kingdom reported no relationship between food safety knowledge of staff and the sanitary condition of the premises (Powell et al., 1997). Additionally, the phenomenon of individuals self-reporting use of correct food safety practices but failing to do so when observed has previously been reported (Patil et al., 2005). A wide discrepancy between farmers' market vendor selfreported food safety practices and researcher and state sanitarian observations specifically demonstrated this disconnect (Scheinberg et al., 2018). Therefore, without observational data, it is difficult to say if the in-facility behavior of the trained employees was truly altered by training. These findings highlight the importance of direct observation and supervision to ensure that desired behaviors presented in training are truly being carried out. Without this knowledge, analysis of the efficacy of an intervention may be difficult.

\section{Neither Training Alone Nor a Combination of Training and Modified CIP Led to Reduced Occurrence of PPC}

Samples of finished product collected from each of the 4 processing facilities at approximately $1 \mathrm{wk}$ before the training or training and chemical intervention (the preliminary sample collection date) were used to assess spoilage due to PPC (S-PPC) over refriger- ated shelf-life (Figures 2A and 2B). Throughout this study, a sample was classified as S-PPC if the sample showed both (1) SPC $>20,000 \mathrm{cfu} / \mathrm{mL}$ for at least $1 \mathrm{~d}$ of shelf-life and (2) either sequencing-confirmed presence of gram-negative bacterial genera or characteristic gram-negative growth on CVTA. Frequency of S-PPC ranged from a low of $1 / 9$ samples (facility I) to a high of $7 / 7$ samples (facility $\mathrm{G}$ ) on this preliminary sample collection date. The $16 \mathrm{~S}$ rDNA sequencing of isolates identified the gram-negative genera Pseudomonas and Acinetobacter in at least 1 sample from each of the 4 facilities from the preliminary sample collection date, whereas Enterobacteriaceae were identified only in samples from facilities C, D, and G, and Stenotrophomonas was isolated only from facility C. Consistent detection of gram-negative PPC in commercially processed HTST-pasteurized milk samples is well established in contemporary literature. For example, Alles et al. (2018) reported that PPC with gram-negative bacteria was detected in 57\% (60 of 105) finished product packages collected from 20 processing facilities, whereas Reichler et al. (2018) found that the frequency of gram-negative PPC in finished product packages collected and averaged over 4 sample collection dates from 10 processing facilities (which included the 4 facilities studied here) ranged from 13 to $74 \%$.

For processing facilities $\mathrm{C}$ and $\mathrm{G}$, which received only training, follow-up samples collected during 3 collection dates after training showed no indication of reduced incidence of S-PPC (Figure 2B). For facility C, S-PPC was determined in $6 / 12,5 / 9$, and $5 / 6$ samples collected 1 mo, 2 to 3 mo, and 6 to 8 mo post-training, compared with 4/10 samples collected on the date before training $(P=0.88)$. Facility $\mathrm{G}$ showed a $100 \%$ incidence of S-PPC throughout this study, with S-PPC determined for $8 / 8,8 / 8$, and 10/10 samples collected on dates 1 mo, 2 to $3 \mathrm{mo}$, and 6 to 8 mo post-training, respectively, as compared with $7 / 7$ samples collected on the date before training. Similarly, we did not find evidence for overall reduction of S-PPC in the 2 facilities where both training and modified CIP were implemented. For facility I, S-PPC was determined for $0 / 7,4 / 7$, and $5 / 7$ samples collected immediately after the intervention, 2 to $3 \mathrm{mo}$ after the intervention, and 6 to 8 mo after the intervention, respectively, as compared with $1 / 9$ samples collected on the date before the intervention $(P=0.71)$. For facility D, S-PPC was determined for $11 / 14,9 / 13$, and $8 / 12$ samples collected immediately after the intervention, $2 \mathrm{wk}$ after the intervention, and 6 to $8 \mathrm{mo}$ after the intervention, respectively, as compared with 11/12 samples collected on the date before the training and modified CIP intervention $(P=0.12)$.

Overall, our data indicate that although employees (filler operators, sanitation staff, and maintenance 


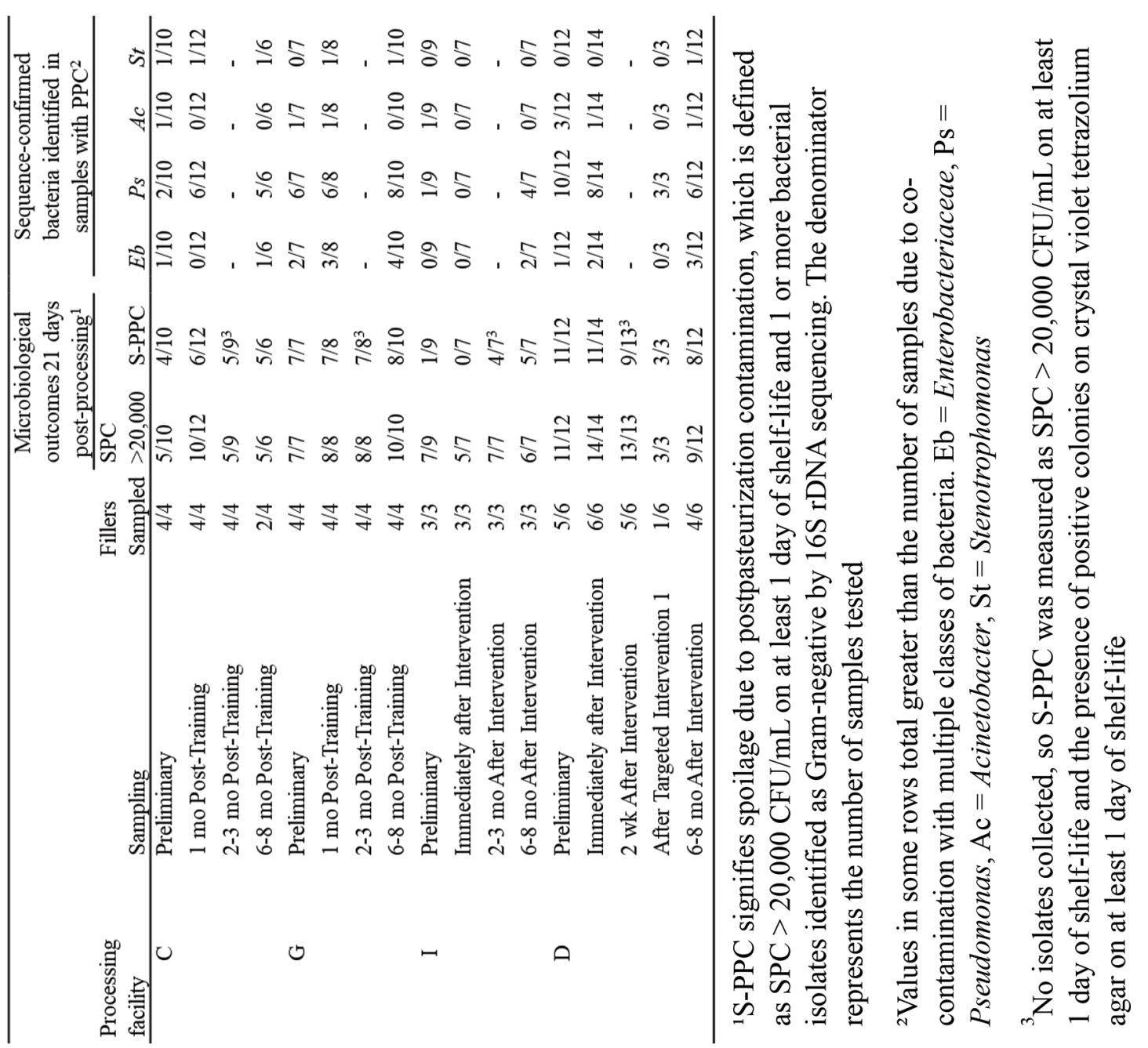

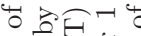

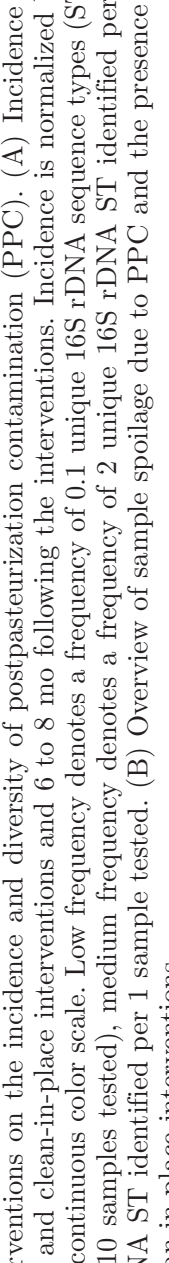

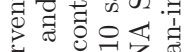

幽.

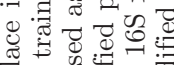

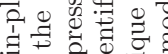

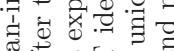

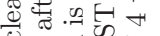

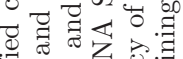

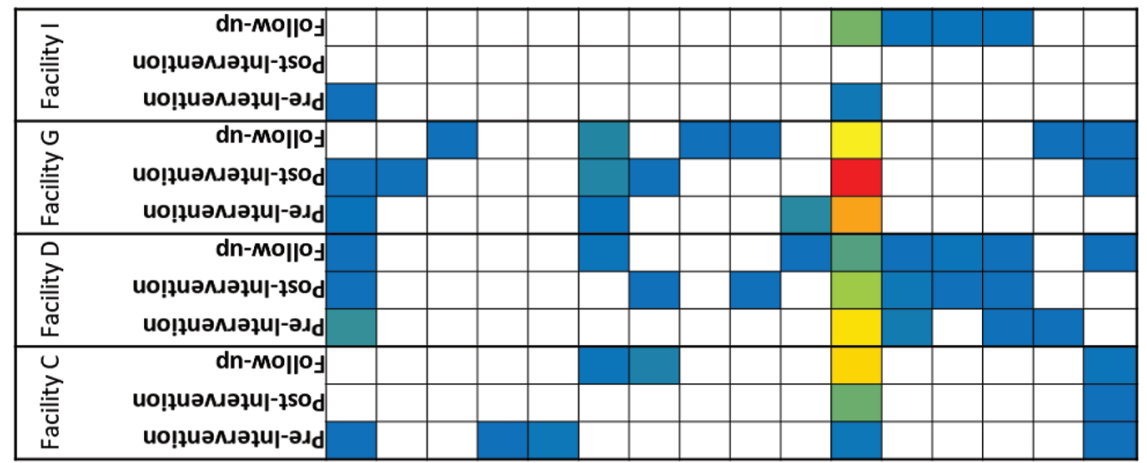

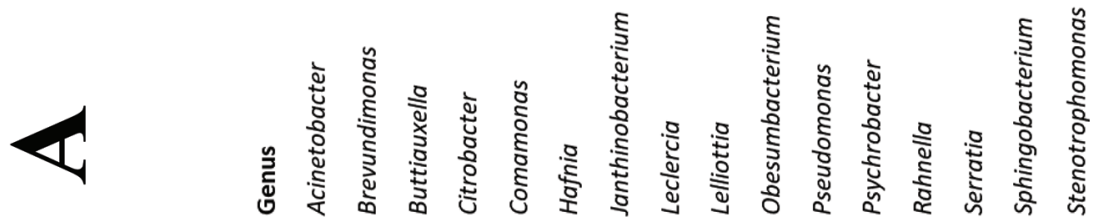

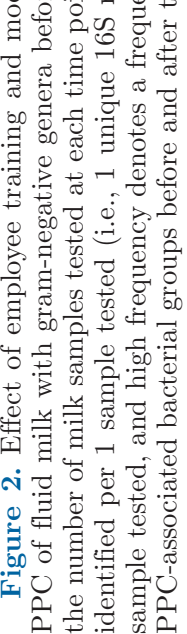


staff) at all 4 facilities received an hour-long GMP training, this did not result in improved milk quality by the assessments performed. Similar negative results were reported by Etter et al. (2017), who found that Listeria monocytogenes prevalence was not significantly reduced in 30 retail delicatessens after implementing new sanitation standard operating procedures. In contrast, training has been demonstrated in other cases to result in significant decreases in the populations of sanitary indicator bacteria in environmental and food samples (Cohen et al., 2001; Machado and Cutter, 2017) as well as on the hands of food handlers (Costa Dias et al., 2012). A possible explanation for the observation that training was not associated with reduced PPC in our study is a lack of recognition or acknowledgment of ongoing quality issues caused by PPC by management at the facilities. For example, facilities may have internal data on a small number of retained samples stored at low refrigeration temperatures that do not reveal sensory defects, which could be interpreted by management as evidence that no quality issues exist (Reichler et al., 2018). Without a sense of urgency surrounding the quality of their milk over shelf-life, it is possible that there was insufficient enforcement by facility management of the ideas and practices presented in training, reducing employee buy-in. The importance of management buy-in to food safety and quality is supported by a recent publication that observed a correlation between retail delicatessen manager food safety culture and incidence of Listeria monocytogenes contamination (Wu et al., 2020). Even more specifically, handwashing among mushroom industry workers was significantly increased in instances of reinforcement of the correct behavior by supervisors (Nieto-Montenegro et al., 2008). Alternatively, the lack of PPC reduction could have been observed even if behaviors were modified if employee behavior was not the primary source of the PPC. In previous studies, contaminated equipment has been identified as the source of PPC, but it is unclear if that contamination was the result of specific employee practices or a consequence of equipment structure, design, and cleanability (Eneroth et al., 2000a, 2001; Mugadza et al., 2019). Regardless of the root cause of the contamination, it is clear that facility management must be committed to ensuring that those they supervise comply with the practices set forth in training.

\section{S rDNA Findings Support That Specific Bacterial Taxonomic Groups Continued to Contribute to PPC Even After Interventions}

To further assess the effect of interventions on SPPC, 16S rDNA sequence typing was performed on all gram-negative isolates obtained from samples collected before and after interventions. Overall, we successfully sequenced 655 gram-negative bacterial isolates collected from fluid milk samples (198 collected before and 457 collected after interventions). These 655 isolates represented 68 unique $16 \mathrm{~S}$ rDNA ST (Table 2). Of these ST, 34 (50\%) represented Pseudomonas, 18 (26.5\%) represented Enterobacteriaceae, 5 (7.4\%) represented Acinetobacter, 1 (1.5\%) represented Stenotrophomonas, and $10(14.7 \%)$ represented other gram-negative genera. Among the 103 samples that had detectable PPC, 66\% contained Pseudomonas, $24 \%$ contained Enterobacteriaceae, $9 \%$ contained Acinetobacter, and 5\% contained Stenotrophomonas (several samples yielded more than 1 genus). The total number of unique ST isolated from a facility ranged from a low of 10 at facility I to a high of 38 at facility D (Table 2). The total number of ST that were identified at multiple sampling dates within a given processing facility ranged from a low of 0 at facility I to a high of 15 at facility D.

For the 2 facilities that received only training (facilities G and C), multiple Pseudomonas ST were found among samples with S-PPC collected both before and after interventions (Table 2 and Figure 2). In addition, Enterobacteriaceae were found in both facilities before and after training, whereas both Acinetobacter and Stenotrophomonas were found before and after training only in facility G. More specifically, for facility C, Pseudomonas was isolated from 2/10 samples collected before the intervention as well as 6/12 and 5/6 samples collected $1 \mathrm{mo}$ and 6 to $8 \mathrm{mo}$ after the intervention. Pseudomonas was isolated from 6/7 samples collected from facility $\mathrm{G}$ before the intervention as well as $6 / 8$ and 8/10 samples collected on dates 1 mo and 6 to 8 mo after the intervention. Enterobacteriaceae were isolated from $2 / 7$ samples collected before training at facility $\mathrm{G}$, whereas on sample collection dates after training Enterobacteriaceae were isolated from $3 / 8$ and $4 / 10$ samples. At facility G, 8 Pseudomonas ST and 1 Hafnia ST were isolated from milk samples obtained on sample collection dates both before and after the training exercise (Table 2). In terms of PPC diversity, no major changes were seen in the Simpson index for the isolates collected from samples from facilities $\mathrm{C}$ and $\mathrm{G}$ on different dates (Table 2). Overall, these data suggested that similar bacterial groups are associated with PPC of samples collected on dates both before and after the training intervention. Pseudomonas as a cause of S-PPC in dairy foods is well and long established (Schultze and Olson, 1960; Cousin, 1982). Pseudomonas has also been isolated from dairy processing facilities and equipment both before and after sanitation (Cleto et al., 2012; Stellato et al., 2017). The importance of Pseudomonas contamination in dairy processing is compounded by 
the myriad spoilage capabilities of Pseudomonas sp., which includes not only flavor and texture but also color defects (Hayes et al., 2002; Rossi et al., 2018). Other gram-negative bacterial genera, such as Acinetobacter and Stenotrophomonas, though isolated fairly frequently from milk with S-PPC in this and a previous study (Reichler et al., 2018), are rarely remarked upon, and their potential for sensory defect production is largely unknown.

No significant change in the frequency of PPC was observed following the implementation of the modified CIP program combined with employee training at facilities I and D (Table 2 and Figure 2). At facility I, only $1 / 9$ samples collected before the intervention showed PPC. This 1 pre-intervention sample yielded both Pseudomonas and Acinetobacter isolates. Only Pseudomonas was isolated from samples collected after the intervention at facility I $(4 / 7$ samples at 6 to 8 mo post-intervention). Overall, $10 \mathrm{ST}$ were identified among the 25 isolates from this facility, and no ST were identified from samples collected both before and after intervention. The Simpson index increased from 0.67 at the preliminary sample collection to 0.82 at 6 to 8 mo post-intervention, demonstrating that bacterial isolate diversity did not decrease over this time. For facility D, Pseudomonas was also the predominant contaminant identified in samples collected on dates before and after the CIP intervention. Pseudomonas was isolated and identified in 10/12 samples collected before the CIP intervention and in 8/14 and 6/12 samples collected on dates immediately after the intervention and 6 to 8 mo after the intervention, respectively. In addition, Enterobacteriaceae were isolated from 1/12 samples collected before, 2/14 samples collected immediately after, and $3 / 12$ samples collected 6 to 8 mo after intervention. Of the 38 ST identified among the 329 gram-negative isolates collected from the 45 facility D milk samples, 11 ST (8 Pseudomonas, 1 Acinetobacter, 1 Psychrobacter, 1 Serratia) were identified in milk samples collected both before and immediately after the modified CIP intervention. Among the ST identified in the samples collected 6 to 8 mo after the CIP intervention, 5 ST (3 Pseudomonas, 1 Acinetobacter, 1 Psychrobacter) were also identified in the samples collected before the primary intervention. Overall, 17 ST were identified from milk samples collected before the CIP intervention and from samples collected on at least 1 sample collection date after the CIP intervention, whereas 20 ST were identified from milk samples collected on any 2 or more sample collection dates. The Simpson indices for isolates collected from facility D milk samples held steady between 0.91 and 0.93 for the 3 sample collec-

Table 2. Summary of $16 \mathrm{~S}$ rDNA sequence type (ST) diversity metrics for isolates identified at all facilities and across all time points

\begin{tabular}{|c|c|c|c|c|c|}
\hline Facility & $\mathrm{C}$ & $\mathrm{G}$ & I & $\mathrm{D}$ & Total $^{1}$ \\
\hline \multicolumn{6}{|l|}{ Cumulative $^{2}$ unique ST obtained from } \\
\hline Preliminary sampling & 6 & 14 & 3 & 17 & 30 \\
\hline First follow-up & 9 & 25 & 3 & 24 & 46 \\
\hline Second follow-up (total unique ST) & 19 & 33 & 10 & 38 & 68 \\
\hline Total number of ST with repeat isolation ${ }^{3}$ & 4 & 11 & 0 & 15 & 20 \\
\hline \multicolumn{6}{|l|}{ ST with repeat isolation, classified into ${ }^{4}$} \\
\hline Enterobacteriaceae & $0(2)$ & $2(8)$ & $0(2)$ & $1(8)$ & $3(18)$ \\
\hline Pseudomonas & $3(12)$ & $8(19)$ & $0(6)$ & $11(22)$ & $13(34)$ \\
\hline Acinetobacter & $0(1)$ & $0(2)$ & $0(1)$ & $2(4)$ & $2(5)$ \\
\hline Stenotrophomonas & $1(1)$ & $1(1)$ & $0(0)$ & $0(0)$ & $1(1)$ \\
\hline Other & $0(3)$ & $0(3)$ & $0(1)$ & $1(4)$ & $1(10)$ \\
\hline \multicolumn{6}{|l|}{ Simpson index of diversity ${ }^{5}$} \\
\hline Preliminary sampling & 0.82 & 0.90 & 0.67 & 0.92 & - \\
\hline First follow-up & 0.72 & 0.93 & $\mathrm{NA}^{6}$ & 0.93 & - \\
\hline Second follow-up & 0.91 & 0.92 & 0.82 & 0.91 & - \\
\hline
\end{tabular}

${ }^{1}$ Values in the total column are equal to or less than the sum of the values in the rows because of identification of the same 16S ST from more than 1 processing facility.

${ }^{2}$ Cumulative frequency over 3 different sample collection dates; for example, the number of ST in the first follow-up row represents all unique ST identified in the preliminary sampling plus any additional unique ST identified at the first follow-up.

${ }^{3}$ Indicates ST isolated on more than 1 sample collection date for a single facility.

${ }^{4}$ Repeat isolation is defined as isolation from samples collected on 2 or more sample collection dates. Parenthetical values represent the total number of ST for each genus, including both ST with and without evidence of repeat isolation.

${ }^{5}$ A measure of diversity that equals 1 - the probability that $2 \mathrm{ST}$ taken at random from the sampling of interest represent the same ST. Higher values indicate higher diversity.

${ }^{6}$ Unable to calculate because no gram-negative isolates were obtained from this sampling. 
tion dates where isolates were identified, indicating no observed change in PPC community diversity over this time period.

The modified CIP program for the interventions in this study was selected because the acid pretreatment and alkaline override are believed to produce soildisrupting bubbles absent in conventional CIP (Man et al., 2011; Fernholz and Erickson, 2018). Additionally, the use of $60^{\circ} \mathrm{C}$ mixed peracid sanitizer in place of lower or ambient temperature sanitizer at the end of CIP is claimed to result in superior bacterial reduction, particularly of sporeformers (Bolduc and McSherry, 2014). One possible explanation for the observation that modified CIP implementation did not reduce PPC is the questionable degree to which facility infrastructure and existing hygienic design support proper CIP performance. Dairy processing equipment that is CIP compatible may be installed or maintained in a manner that is not conducive to the action of CIP systems. The same may be true for small articles, such as gaskets and O-rings, which may increase microbial harborage with age, condition, and mode of use (Mettler and Carpentier, 1997; Storgards et al., 1999). We are not aware of any peer-reviewed studies that have examined the efficacy of real-world (i.e., in a commercial processing facility) CIP for dairy processing equipment such as filling machines. Biofilms are often blamed for quality problems in food and dairy processing, though they are difficult to find and accurately diagnose (Austin and Bergeron, 1995; Cherif-Antar et al., 2016). The lack of PPC reduction could also be because critical components of dairy processing equipment (e.g., filler nozzles) must be manually cleaned rather than undergo CIP, consistent with previous studies reporting filler nozzles as the likely source of repeat Pseudomonas (Ralyea et al., 1998) and Bacillus (Mugadza et al., 2019) contamination of fluid milk. Overall, it appears that enhanced sanitation chemistry cannot be relied upon as a panacea for eliminating PPC resulting from unknown or ambiguous contamination sources within a facility. Rather, our data suggest that whatever sanitation problems are causing PPC must be discovered and addressed individually to resolve persistent contamination, supporting the need for stringent root-cause analysis procedures.

\section{PM Targeting a Single Filler Reduced PPC Incidence}

In facility D, a specific filler (Gable-Top Carton Filler 2) was identified for a PM intervention based on a preexisting in-facility PM schedule. For a point of comparison, a second application of the modified CIP intervention was performed on this filler approximately
1 mo before changeout of used rubber goods. Following the second application of the modified CIP intervention, $3 / 3$ samples collected from this filler showed S-PPC. All 3 samples were contaminated with Pseudomonas. Of the 4 ST of Pseudomonas identified from this sample collection date, ST 13 was found in all 3 samples. This incidence rate and composition of S-PPC is similar to that identified before the first application of the training and modified CIP intervention (all 3 samples collected from this filler showed S-PPC; Figure 2B).

After the PM intervention, S-PPC was detected in only $1 / 3$ collected samples; Pseudomonas isolated from this sample represented 2 ST (10 and 16). In addition to testing the milk samples, the used rubber goods ( 85 gaskets and O-rings) from this filler were pooled by filler location for recovery of PPC-associated bacteria. Gram-negative bacterial genera were isolated from 6 of these pooled samples, including Pseudomonas, Psychrobacter, and Stenotrophomonas (5, 1, and 1 of the pooled samples, respectively). Isolates from the rubber goods represented 8 ST (6 Pseudomonas, 1 Psychrobacter, 1 Stenotrophomonas), 3 of which (all Pseudomonas) were also isolated from milk samples packaged on this filler. Similar to our results, Ralyea et al. (1998) found that PPC originating from a rotary filler could be substantially reduced by replacing the degraded rubber filler nozzles. One limitation of our study reported here is the low number of samples collected. Although the incidence of PPC was reduced from $3 / 3$ samples collected before the PM intervention to $1 / 3$ samples collected after its application, the statistical and biological significance of this decrease requires further evaluation for generalizable conclusions to be drawn. However, this case study does suggest that regular implementation of PM may be an important factor in controlling microbial harborage in fluid milk processing lines.

\section{gInS-recA Allelic Typing Demonstrated High Diversity of Pseudomonas Within a Subset of $16 S$ rDNA ST 13 Isolates}

To assess the microbial diversity of Pseudomonas ST isolated from samples with S-PPC using a more sensitive genetic comparison, the partial $g \ln S$ and $\operatorname{rec} A$ sequences were obtained from 41 facility D Pseudomonas isolates with $16 \mathrm{~S}$ rDNA ST 13. These data were used to investigate the repeated contamination of milk from Gable-Top Carton Filler 2 (Figure 3). These isolates originated from 5 milk samples collected on 3 sample collection dates (after the training and modified CIP intervention, after the second modified CIP intervention performed only on this filler, and before the PM intervention), and from 2 pooled samples of gaskets 


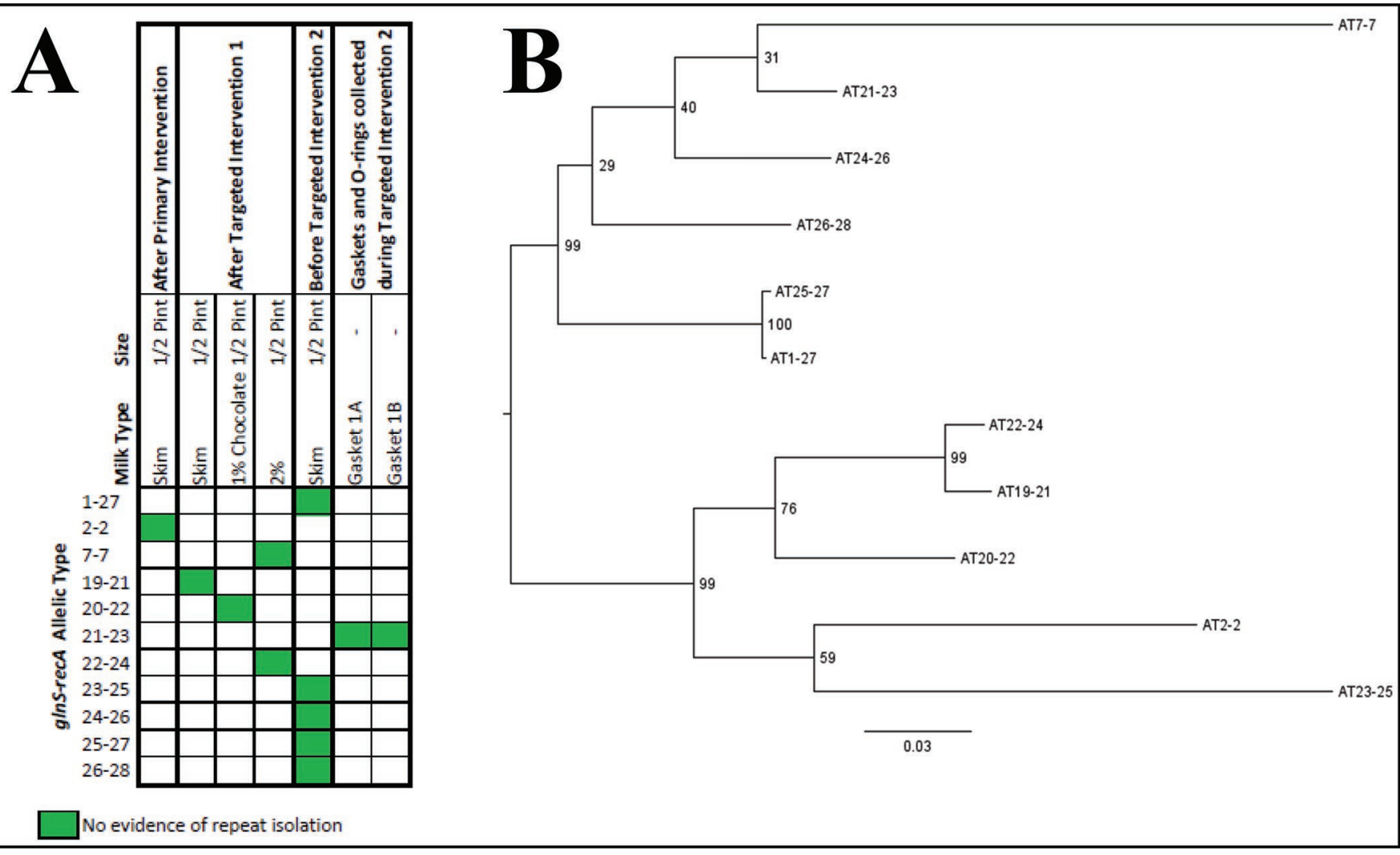

Figure 3. Effect of a preventive maintenance intervention on diversity of postpasteurization contamination. (A) $g l n S$-recA allelic type matrix for Pseudomonas isolates with 16S rDNA sequence type 13 from milk and rubber goods samples from Gable-Top Carton Filler 2 (Evergreen Packaging, Memphis, TN) at processing facility D. (B) $g l n S-r e c A$ allelic type maximum likelihood phylogenetic tree of isolates with $16 \mathrm{~S}$ rDNA sequence type 13 from milk and rubber goods samples from Gable-Top Carton Filler 2 at processing facility D. The number of bootstrap replicates are displayed next to the nodes. The scale bar represents the number of nucleotide substitutions per site.

and O-rings collected during the PM intervention. This set of 41 isolates with identical $16 \mathrm{~S}$ ST represented 11 unique $g \ln S$-recA AT, indicating (1) enhanced discriminatory power of $g \ln S$-recA sequencing and (2) considerable diversity within a single $16 \mathrm{~S}$ ST. A median of 3 isolates and a maximum of 9 isolates were identified for each assigned $g \ln S-r e c A$ AT. A minimum of 1 and a maximum of $5 \mathrm{~g} \ln S$-recA AT were identified from each milk or rubber goods sample. The $g \ln S-r e c A$ AT $21-23$ was isolated from 2 pooled rubber goods samples, but this AT was not isolated from any of the milk samples collected from this filler. Whereas the 41 isolates all had the same $16 \mathrm{~S} \mathrm{ST}$, no common $g \ln S$-recA AT were identified from samples originating from different sample collection dates or from both milk and rubber goods samples. This suggests that no particular Pseudomonas strains survived over this time period within this filler, but rather that taxonomically similar Pseudomonas (as supported by identical partial $16 \mathrm{~S}$ rDNA sequences) temporarily contaminated this filler across multiple sample collection dates. Finding higher bacterial di- versity than was determined by $16 \mathrm{~S}$ rDNA sequencing when using a more sensitive subtyping tool, such as MLST, is expected and demonstrates the advantages of using higher resolution subtyping techniques (Jolley and Maiden, 2014). These findings highlight the importance of using high-resolution subtyping techniques before declaring that a particular bacterial strain is persistent in a facility or piece of equipment. Although these data suggest that a facility or piece of equipment may simply serve as a niche that selects for a particular group of closely related organisms that are continually being introduced from the outside environment and do not survive or persist over a long period of time, further subtyping studies are clearly needed to assess persistence of gram-negative bacteria that cause PPC in fluid milk processing facilities.

\section{CONCLUSIONS}

Implementation of a 1-h employee training both with and without the application of a modified CIP 
intervention failed to decrease the incidence or diversity of spoilage due to gram-negative PPC within the timeframe of this study, despite an increase in employee knowledge immediately following the training and self-reported long-term behavior changes. However, a regularly scheduled PM intervention that targeted replacement of wearable rubber goods within a specific package filler did result in decreased frequency of PPC in finished products, though these results are based on a limited number of samples. Our case study results demonstrated the inherent difficulties of identifying and successfully addressing sanitation problems in large and complex fluid milk processing facilities. This suggests that although short-term evaluations of intervention success, such as pre- and post-tests for employee training, are often used to measure the effect of corrective and preventive actions, more sensitive microbial tests performed on larger sample sets collected from real processing conditions may be necessary to evaluate the effectiveness of different PPC interventions.

\section{ACKNOWLEDGMENTS}

This work was funded by the National Dairy Council (Rosemont, IL; OSP \# 73849) and by the New York State Dairy Promotion Advisory Board (Albany, NY; OSP \# 83562) through the New York State Department of Agriculture and Markets (Albany, NY). The CIP chemicals used for the modified CIP program were provided at no cost to the participating processing facilities by Ecolab Inc. (St. Paul, MN). We thank the students, faculty, and staff of the Cornell University Milk Quality Improvement Program, the Cornell University Food Safety Laboratory, and the Cornell University Dairy Extension for their work to support this project. Additionally, we thank the management and employees of our participating processors, who allowed us into their facilities to observe and train. One of the co-authors (AWE) is employed by Ecolab Inc. (St. Paul, MN), a company that provides sanitation solutions for food processors. The remaining authors have not stated any conflicts of interest.

\section{REFERENCES}

Alles, A. A., M. Wiedmann, and N. H. Martin. 2018. Rapid detection and characterization of postpasteurization contaminants in pasteurized fluid milk. J. Dairy Sci. 101:7746-7756. https://doi.org/ $10.3168 /$ jds.2017-14216.

Andreani, N. A., M. E. Martino, L. Fasolato, L. Carraro, F. Montemurro, R. Mioni, P. Bordin, and B. Cardazzo. 2015. Reprint of 'tracking the blue: A MLST approach to characterise the Pseudomonas fluorescens group. Food Microbiol. 45:148-158. https://doi .org/10.1016/j.fm.2014.11.011.

Asteriadou, K., and P. Fryer. 2009. Assessment of Cleaning Efficiency. Pages 164-177 in Cleaning-in-Place. Blackwell Publishing Ltd., Oxford, UK.
Austin, J. W., and G. Bergeron. 1995. Development of bacterial biofilms in dairy processing lines. J. Dairy Res. 62:509-519. https:/ doi.org/10.1017/S0022029900031204.

Bates, D., M. Mächler, B. Bolker, and S. Walker. 2015. Fitting linear mixed-effects models using lme4. J. Stat. Softw. 67:1-48. https:// doi.org/10.18637/jss.v067.i01.

Bolduc, J. W., and D. D. McSherry, inventors. 2014. Enhanced microbial peracid compositions and methods of use at reduced temperatures in aseptic cleaning. Ecolab USA Inc., assignee. US Pat. No. $8,883,848$ B2.

Burgess, K. J. 2009. Management of CIP operations. Pages 178-194 in Cleaning-in-Place: Dairy, Food and Beverage Operations. 3rd ed. A. Tamime, ed. Blackwell Publishing Ltd., Oxford, UK. https:// doi.org/10.1002/9781444302240.ch9.

Buzby, J., H. Farah-Wells, and J. Hyman. 2014. The estimated amount, value, and calories of postharvest food losses at the retail and consumer levels in the united states. USDA-ERS Economic Information Bulletin Number 121. Accessed Jan. 9, 2020. https:// ssrn.com/abstract $=2501659$.

Cherif-Antar, A., B. Moussa-Boudjemâa, N. Didouh, K. Medjahdi, B. Mayo, and A. B. Flórez. 2016. Diversity and biofilm-forming capability of bacteria recovered from stainless steel pipes of a milkprocessing dairy plant. Dairy Sci. Technol. 96:27-38. https://doi .org/10.1007/s13594-015-0235-4.

Cleto, S., S. Matos, L. Kluskens, and M. J. Vieira. 2012. Characterization of contaminants from a sanitized milk processing plant. PLoS One 7:e40189. https://doi.org/10.1371/journal.pone.0040189.

Cohen, E., A. Reichel, and Z. Schwartz. 2001. On the efficacy of an in-house food sanitation training program: Statistical measurements and practical conclusions. J. Hosp. Tour. Res. (Wash. D.C.) 25:5-16. https://doi.org/10.1177/109634800102500102.

Cole, J. R., Q. Wang, E. Cardenas, J. Fish, B. Chai, R. J. Farris, A. S. Kulam-Syed-Mohideen, D. M. McGarrell, T. Marsh, G. M. Garrity, and J. M. Tiedje. 2009. The ribosomal database project: Improved alignments and new tools for rRNA analysis. Nucleic Acids Res. 37(Database):D141-D145. https://doi.org/10.1093/ nar/gkn879.

Costa Dias, M. A., A. S. Sant'Ana, A. G. Cruz, J. A. F. Faria, C. A. Fernandes de Oliveira, and E. Bona. 2012. On the implementation of good manufacturing practices in a small processing unity of mozzarella cheese in Brazil. Food Control 24:199-205. https://doi .org/10.1016/j.foodcont.2011.09.028.

Cousin, M. A. 1982. Presence and activity of psychrotrophic microorganisms in milk and dairy products: A review. J. Food Prot. 45:172-207. https://doi.org/10.4315/0362-028X-45.2.172.

da Cunha, D. T., E. Stedefeldt, and V. V. de Rosso. 2014. The role of theoretical food safety training on Brazilian food handlers' knowledge, attitude and practice. Food Control 43:167-174. https://doi .org/10.1016/j.foodcont.2014.03.012.

De Schweinitz, E. A. 1894. The pasteurization and sterilization of milk. Pages 331-356 in Yearbook of the United States Department of Agriculture: 1894. Government Printing Office, Washington, DC.

Egan, M. B., M. M. Raats, S. M. Grubb, A. Eves, M. L. Lumbers, M. S. Dean, and M. R. Adams. 2007. A review of food safety and food hygiene training studies in the commercial sector. Food Control 18:1180-1190. https://doi.org/10.1016/j.foodcont.2006.08.001.

Ehiri, J. E., G. P. Morris, and J. McEwen. 1997. Evaluation of a food hygiene training course in Scotland. Food Control 8:137-147. https://doi.org/10.1016/S0956-7135(97)00005-4.

Eneroth, Å., S. Ahrné, and G. Molin. 2000a. Contamination of milk with Gram-negative spoilage bacteria during filling of retail containers. Int. J. Food Microbiol. 57:99-106. https://doi.org/10 .1016/S0168-1605(00)00239-7.

Eneroth, Å., S. Ahrné, and G. Molin. 2000b. Contamination routes of Gram-negative spoilage bacteria in the production of pasteurised milk, evaluated by randomly amplified polymorphic DNA (RAPD). Int. Dairy J. 10:325-331. https://doi.org/10.1016/S0958 -6946(00)00055-8.

Eneroth, Å., B. Svensson, G. Molin, and A. Christiansson. 2001. Contamination of pasteurized milk by Bacillus cereus in the fill- 
ing machine. J. Dairy Res. 68:189-196. https://doi.org/10.1017/ S002202990100485X.

Etter, A. J., S. R. Hammons, S. Roof, C. Simmons, T. Wu, P. W. Cook, A. Katubig, M. Stasiewicz, E. Wright, S. Warchocki, J. Hollingworth, H. S. Thesmar, S. A. Ibrahim, M. Wiedmann, and H. F. Oliver. 2017. Enhanced sanitation standard operating procedures (SSOPs) have limited impact on Listeria monocytogenes prevalence in retail delis. J. Food Prot. 80:1903-1912. https://doi.org/ 10.4315/0362-028X.JFP-17-112.

Fernholz, P. J., and A. W. Erickson, inventors. 2018. Bubble enhanced cleaning method and chemistry. Ecolab USA Inc., assignee. US Pat. No. 10,099,264 B2.

Frank, J. F., and A. E. Yousef. 2004. Tests for groups of microorganisms. In Standard Methods for the Examination of Dairy Products. 17th ed. H. M. Wehr and J. F. Frank, ed. American Public Health Association, Washington, DC.

Havighorst, C. R. 1957. Cleaning system automated. Food Eng. 29:100-105.

Hayes, W., C. H. White, and M. A. Drake. 2002. Sensory aroma characteristics of milk spoilage by Pseudomonas species. J. Food Sci. 67:448-454. https://doi.org/10.1111/j.1365-2621.2002.tb11427.x.

Jolley, K. A., and M. C. Maiden. 2014. Using MLST to study bacterial variation: Prospects in the genomic era. Future Microbiol. 9:623-630. https://doi.org/10.2217/fmb.14.24.

Koehler, G., and F. O. Tonney. 1911. The control of pasteurization. J. Am. Med. Assoc. 56:713-718. https://doi.org/10.1001/jama.1911 .02560100005003 .

Laird, D. T., S. A. Gambrel-Lenarz, F. M. Scher, T. E. Graham, and R. Reddy. 2004. Microbiological count methods. In Standard Methods for the Examination of Dairy Products. 17th ed. H. M. Wehr and J. F. Frank, ed. American Public Health Association, Washington, DC.

Larsson, A. 2014. AliView: A fast and lightweight alignment viewer and editor for large datasets. Bioinformatics 30:3276-3278. https:/ /doi.org/10.1093/bioinformatics/btu531.

Machado, R. A. M., and C. N. Cutter. 2017. Sanitation indicators as a tool to evaluate a food safety and sanitation training program for farmstead cheese processors. Food Control 78:264-269. https://doi .org/10.1016/j.foodcont.2017.02.039.

Machado, R. A. M., and C. N. Cutter. 2018. Training hard-to-reach Pennsylvanian cheesemakers about food safety, using a low-tech training tool. Food Prot. Trends 38:266-283.

Man, V. F.-P., G. M. Fasching, N. D. Peitersen, and M. R. Altier, inventors. 2011. Neutral or alkaline medium chain peroxycarboxylic acid compositions and methods employing them. Ecolab USA Inc., assignee. US Pat. No. 7,887,641 B2.

Martin, N. H., K. J. Boor, and M. Wiedmann. 2018. Symposium review: Effect of post-pasteurization contamination on fluid milk quality. J. Dairy Sci. 101:861-870. https://doi.org/10.3168/jds .2017-13339.

Martin, N. H., N. R. Carey, S. C. Murphy, M. Wiedmann, and K. J. Boor. 2012. A decade of improvement: New York State fluid milk quality. J. Dairy Sci. 95:7384-7390. https://doi.org/10.3168/jds 2012-5767.

Mettler, E., and B. Carpentier. 1997. Location, enumeration and identification of the microbial contamination after cleaning of EPDM gaskets introduced into a milk pasteurization line. Lait 77:489503. https://doi.org/10.1051/lait:1997435.

Moerman, F., P. Rizoulières, and F. A. Majoor. 2014. Cleaning in place (CIP) in food processing. Pages $305-383$ in Hygiene in Food Processing: Principles and Practice. 2nd ed. H. L. M. Lelieveld, J. T. Holah, and D. Napper, ed. Woodhead Publishing, Oxford, UK. https://doi.org/10.1533/9780857098634.3.305.

Monrad, J. H. 1895. Pasteurization and milk preservation: With a chapter on selling milk. J. H. Monrad, Winnetka, IL.

Moseley, W. K. 1980. Pinpointing post-pasteurization contamination. J. Food Prot. 43:414. https://doi.org/10.4315/0362-028X-43.5.414.

Mugadza, D. T., R. Owusu-Darko, and E. M. Buys. 2019. Short communication: Source tracking Bacillus cereus in an extended shelflife milk processing plant using partial sequencing of $r p o B$ and multilocus sequence typing. J. Dairy Sci. 102:135-139. https://doi .org/10.3168/jds.2018-14733.

Murphy, S. I., D. Kent, N. H. Martin, R. L. Evanowski, K. Patel, S. M. Godden, and M. Wiedmann. 2019. Bedding and bedding management practices are associated with mesophilic and thermophilic spore levels in bulk tank raw milk. J. Dairy Sci. 102:6885-6900. https://doi.org/10.3168/jds.2018-16022.

Nieto-Montenegro, S., J. L. Brown, and L. F. LaBorde. 2008. Development and assessment of pilot food safety educational materials and training strategies for Hispanic workers in the mushroom industry using the health action model. Food Control 19:616-633. https:// doi.org/10.1016/j.foodcont.2007.07.005.

Padilla-Zakour, O. I. 2009. Good manufacturing practices. Pages 395414 in Microbiologically Safe Foods. N. L. Heredia, I. V. Wesley, and J. S. Garcia, ed. John Wiley \& Sons, Hoboken, NJ.

Patil, S. R., S. Cates, and R. Morales. 2005. Consumer food safety knowledge, practices, and demographic differences: Findings from a meta-analysis. J. Food Prot. 68:1884-1894. https://doi.org/10 $.4315 / 0362-028 \mathrm{X}-68.9 .1884$.

Powell, S. C., R. W. Attwell, and S. J. Massey. 1997. The impact of training on knowledge and standards of food hygiene: A pilot study. Int. J. Environ. Health Res. 7:329-334. https://doi.org/10 $.1080 / 09603129773788$.

Priyam, A., B. J. Woodcroft, V. Rai, A. Munagala, I. Moghul, F. Ter, M. A. Gibbins, H. Moon, G. Leonard, W. Rumpf, and Y. Wurm. 2015. SequenceServer: A modern graphical user interface for custom BLAST databases. bioRxiv. https://doi.org/10.1101/033142.

Ralyea, R. D., M. Wiedmann, and K. J. Boor. 1998. Bacterial tracking in a dairy production system using phenotypic and ribotyping methods. J. Food Prot. 61:1336-1340. https://doi.org/10.4315/ 0362-028X-61.10.1336.

R Core Team. 2019. R: A language and environment for statistical computing. R Foundation for Statistical Computing, Vienna, Austria.

Reichler, S. J., A. Trmčić, N. H. Martin, K. J. Boor, and M. Wiedmann. 2018. Pseudomonas fluorescens group bacterial strains are responsible for repeat and sporadic postpasteurization contamination and reduced fluid milk shelf life. J. Dairy Sci. 101:7780-7800. https://doi.org/10.3168/jds.2018-14438.

Rossi, C., A. Serio, C. Chaves-López, F. Anniballi, B. Auricchio, E. Goffredo, B. T. Cenci-Goga, F. Lista, S. Fillo, and A. Paparella. 2018. Biofilm formation, pigment production and motility in Pseudomonas spp. isolated from the dairy industry. Food Control 86(Supplement C):241-248. https://doi.org/10.1016/j.foodcont .2017.11.018.

Russell, H. L. 1895. Pasteurization of milk and cream for direct consumption. University of Wisconsin Agricultural Experiment Station Bulletin 44:3-48.

Scheinberg, J. A., R. Radhakrishna, J. A. Campbell, and C. N. Cutter. 2018. A comprehensive needs assessment of food safety practices of farmers' market vendors in Pennsylvania using direct concealed observations, self-reported surveys, and state sanitarian surveys. Food Prot. Trends 38:421-439.

Schröder, M. J. 1984. Origins and levels of post pasteurization contamination of milk in the dairy and their effects on keeping quality. J. Dairy Res. 51:59-67. https://doi.org/10.1017/S0022029900023323.

Schultze, W. D., and J. C. Olson Jr.. 1960. Studies on psychrophilic bacteria. I. Distribution in stored commercial dairy products. J. Dairy Sci. 43:346-350. https://doi.org/10.3168/jds.S0022 $-0302(60) 90168-5$.

Smith, C. D. 1896. A preliminary bulletin on the pasteurization of milk. Michigan Agricultural Experiment Station Bulletin 134:1543.

Soxhlet, F. 1886. Über kindermilch und säuglings-ernährung. Munch. Med. Wochenschr. 33:253-256., 276-278.

Stamatakis, A. 2014. RAxML version 8: A tool for phylogenetic analysis and post-analysis of large phylogenies. Bioinformatics 30:13121313. https://doi.org/10.1093/bioinformatics/btu033.

Stellato, G., D. R. Utter, A. Voorhis, M. De Angelis, A. M. Eren, and D. Ercolini. 2017. A few Pseudomonas oligotypes dominate in the 
meat and dairy processing environment. Front. Microbiol. 8. https: //doi.org/10.3389/fmicb.2017.00264.

Storgards, E., H. Simola, A. M. Sjöberg, and G. Wirtanen. 1999. Hygiene of gasket materials used in food processing equipment part 1: New materials. Food Bioprod. Process. 77:137-145. https://doi .org $/ 10.1205 / 096030899532286$.

Sunga, F. C. A., D. R. Heldman, and T. I. Hedrick. 1970. Microorganisms from arms and hands of dairy plant workers. J. Milk Food Technol. 33:178-181. https://doi.org/10.4315/0022-2747-33.5.178.

Thomas, S. B. and R. G. Druce. 1969. Psychrotrophic bacteria in refrigerated pasteurised milk. A review. Dairy Industries 34:430-433, 501-505.

Tsarouhas, P. 2007. Implementation of total productive maintenance in food industry: A case study. J. Qual. Mainten. Eng. 13:5-18. https://doi.org/10.1108/13552510710735087.

Vangay, P., E. B. Fugett, Q. Sun, and M. Wiedmann. 2013. Food microbe tracker: A web-based tool for storage and comparison of food-associated microbes. J. Food Prot. 76:283-294. https://doi .org/10.4315/0362-028X.JFP-12-276.
Wu, S. T., S. R. Hammons, R. Silver, J. A. Neal, and H. F. Oliver. 2020. Retail deli managers and associates have better food safety culture in stores with lower Listeria monocytogenes contamination. Food Control 110:106983. https://doi.org/10.1016/j.foodcont.2019 .106983 .

Zugarramurdi, A., M. A. Parin, L. Gadaleta, and H. M. Lupin. 2007. A quality cost model for food processing plants. J. Food Eng. 83:414-421. https://doi.org/10.1016/j.jfoodeng.2007.03.029.

\section{ORCIDS}

S. J. Reichler () https://orcid.org/0000-0001-5288-2517

S. I. Murphy 자 https://orcid.org/0000-0001-9092-0625

A. W. Erickson ( ) https://orcid.org/0000-0003-1388-8312

N. H. Martin () https://orcid.org/0000-0003-1704-0634

M. Wiedmann ( https://orcid.org/0000-0002-4168-5662 